\title{
COMPARATIVE CLINICAL STUDY BETWEEN TUNNEL AND VISTA APPROACHES FOR THE TREATMENT OF MULTIPLE GINGIVAL RECESSIONS WITH ACELLULAR DERMAL MATRIX ALLOGRAFT
}

\author{
Ahmed Dardir Mohamed* and Lama H. Marssafy ${ }^{* *}$
}

\begin{abstract}
Introduction: Gingival recession results from apical migration of the gingival margin leading to root exposure with esthetical and functional problems. Treatment of gingival recession occurs through variable techniques as laterally positioned flaps, coronally advanced flaps, connective tissue graft, tunnel technique and guided tissue regeneration. Acellular Dermal Matrix allograft (ADM) is a safe alternative to autogenous grafts allows the treatment of multiple adjacent recessions. The tunnel technique (Tun) provides good vascularity with absence of the vertical releasing incision. Modification of tunnel technique, vestibular incision subperiosteal tunnel access (VISTA) preserve the papillary integrity and enhances patient's compliance.
\end{abstract}

Materials and Methods: A split mouth study design was done on ten patients having bilaterally symmetrical maxillary or mandibular two to three adjacent Miller Class I or II gingival recession defects on canine or premolars. In each patient, gingival recession will be treated with VISTA+ADM at the right side and TUN+ADM at the left side.

Results: After 6 months follow-up period a statistical significant difference exists between (VISTA+ADM) and (Tun+ADM) sides regarding recession heights and clinical attachment level in favor of (VISTA+ADM) technique. Also a statistically significant difference exists between baseline and 6 months follow-up measurements within each group regarding recession height, clinical attachment level, width of keratinized gingiva and probing depth.

Conclusion: Acellular Dermal Matrix allograft is recommended in treatment of multiple gingival recessions. The combination of VISTA+ADM technique found to be more efficient than Tun+ ADM in treatment of Miller class I and II gingival recessions and led to favorable root coverage.

KEYWORD: Gingival recession, Acellular Dermal Matrix allograft, tunnel technique, vestibular incision subperiosteal tunnel access.

* Assistant Professor of Oral Medicine, Oral Diagnosis and Periodontology, Faculty of Oral and Dental Medicine, Ahram Canadian University, Egypt and umm- Al-Qura University, KSA.

** Assistant Professor of Oral Medicine, Oral Diagnosis and Periodontology, Department of Basic and Clinical Oral Sciences, Collage of Dentistry, Umm Al Qura University, KSA. 


\section{INTRODUCTION}

Gingival recession (GR) is considered one of the most common periodontal problems that results from migration of the gingival margin in an apical direction with exposure of the root. ${ }^{1}$ Esthetical and functional problems as hypersensitivity, root caries and difficulty in oral hygiene will exist following the occurrence of root exposure. ${ }^{2}$ Various causes may lead to gingival recession as trauma from brushing, teeth malposioning, prominent roots, frenum pull, inadequate thickness of attached gingiva or other iatrogenic factors as inadequate periodontal or restorative treatments.-5 Gingival recession classification according to Miller's is divided into four classes. Class I: The margin of the recession does not reach the mucogingival junction and no soft tissue or bone loss occurs at the interdental area. Class (II): The margin of the recession reached the mucogingival junction and no soft tissue or bone loss occurs at the interdental area. Class (III): Recession margin extends to or beyond mucogingival junction and soft tissue or bone loss occurs at the interdental area or tooth malposition. Class (IV): Recession margin extends to or beyond mucogingival junction and severe soft tissue or bone loss occurs at the interdental area or severe tooth malposition. ${ }^{6}$ Several modalities are used in the treatment of gingival recession with variable rate of predictability in their success as laterally positioned flaps, coronally advanced flaps, connective tissue graft, tunnel technique and guided tissue regeneration. ${ }^{7-9}$ Connective tissue graft is considered the gold standard technique, however the limited amount of donor tissues, technique sensitivity and post operative patient's discomfort all considered as disadvantages for this technique. ${ }^{10}$ Cases which have multiple gingival recessions in adjacent teeth require a large volume from donor tissue, and for the patient comfort the covering of adjacent teeth better to be done within the same operation. ${ }^{11}$ Acellular Dermal Matrix (ADM) allograft is a bioactive dermal matrix chemically processed to remove all epidermal and dermal cells. It is a safe alternative to autogenous grafts allows the treatment of multiple adjacent teeth and overcoming the anatomical limitation of the palate. ${ }^{12-15}$ The introduction of non-invasive techniques as envelope, tunnel technique (TUN) had reduces the struggles in other invasive operations and provide good vascularity due to absence of the vertical releasing incision. Homa Zadeh in 2011 introduced a conservative modification in tunnel technique; vestibular incision subperiosteal tunnel access (VISTA) which preserve the papillary integrity and enhances patients compliance. ${ }^{16}$ Vista technique allows gingival tissue regeneration through subperiosteal undermining of soft tissues using a vestibular incision instead of elevating the whole flap. ${ }^{17}$

The present split mouth study was designed to clinically compare between Tunnel and VISTA approaches for the treatment of multiple gingival recessions with acellular dermal matrix

\section{MATERIALS AND METHODS}

Ten systemically healthy, nonsmoker patients were selected from outpatient clinic at faculty of dentistry Umm Al-Qura University to participate in the present split mouth study. Their age ranging from 34- 60 years having bilateral maxillary or mandibular two to three adjacent Miller Class I or II gingival recession defects on canine or premolars. Exclusion criteria included any patients having infectious disease, pregnant female or any patient taking steroid or any medication known to cause gingival enlargement. Initial therapy was done for one month including oral hygiene instructions and periodontal debridement. All surgeries were carried out after informing the patient the aim of the study and informed consent was signed. In each patient, gingival recession will be treated with VISTA+ADM at the right side and TUN+ADM at the left side. 


\section{Evaluation of clinical parameters:}

The clinical parameters recorded mid-bucally with UNC 15 Color-Coded Probe preoperatively (fig 3,15 ) and after six months follow-up period and were as follows:

1. Recession height (RH): measured from cementenamel junction (CEJ) to the gingival margin.

2. Probing depth (PD)

3. Clinical attachment level (CAL): measured by calculating RH + Probing Depth.

4. Width of keratinized gingiva (WKG): measured from gingival margin to the mucogingival junction.

\section{Surgical technique}

The selected cases exhibited maxillary or mandibular bilateral adjacent multiple recession defects (fig 1). Three weeks interval was left between both surgeries to allow initial healing and provide patient comfort during eating. A profound local anesthesia using (Mepivacaine hydrochloride* $0.020 \mathrm{~g} / \mathrm{ml}$ and adrenaline base $0.010 \mathrm{mg} / \mathrm{ml}$ ) was done. On the right side (fig 2) the VISTA technique was applied and started with vestibular incision mesial to the gingival recession defects to be treated (fig 4). Through this access a subperiosteal tunnel was created using Allen oral plastic surgery kit (fig $5)$. The tunnel was extended one tooth beyond the teeth needed root coverage for easier mobilization of gingival margins and facilitating movement of the flap in coronal direction. This subperiosteal elevation was also extended under each papilla whenever the interproximal space permitted. No surface incisions were done through any papilla. Root preparation was done by Younger-Good curette to obtain a smooth clean surface. The flap was then advanced coronally using a horizontal mattress suture at approximately 2-3 $\mathrm{mm}$ apical to gingival margin of each tooth (fig 6). Sutures were tied with the knots at the mid-coronal point of the facial surface of the tooth. The knot was secured with composite resin to restrain any apical movement of the tissues during the initial period of healing (fig 7). ADM** that was soaked in saline solution for 30 minutes and had a thickness of approximately 1 to $1.5 \mathrm{~mm}$ was used (fig 8). It was trimmed lengthwise to the site's adjacent line angles then inserted through the subperiosteal tunnel with help of an elevator or pulled through the tunnel with a suture at the level of CEJ (fig 9). The basement membrane matrix side was placed in contact of the flap, while the dermal side was placed facing the root surface. ADM was sutured to the flap using multiple anchor sutures. The vertical incision was then approximated and sutured (fig 10).

At the left side (fig 14) the tunnel technique was applied by sulcular incision around each tooth. Through the sulcular incision a tunnel was created using Allen oral plastic surgical kit (fig 16). The tunnel was extended till at least one tooth beyond the teeth needed root coverage. Flap elevation continued apically to loosen the pouch and enable coronal advancement. The papillary tissue was lifted without cutting from the alveolar crests. Root preparation was done by Younger-Good curette to obtain a smooth clean surface. ADM was soaked in saline solution for 30 minutes and had a thickness of approximately 1 to $1.5 \mathrm{~mm}$. It was trimmed lengthwise to the site's adjacent line angles then inserted through the tunnel at the level of CEJ (fig 17). The basement membrane matrix side was in contact with the flap, while the dermal side was placed facing the root surface. 6-0 polypropylene suture was used to secure the allograft to the teeth and the flap was closed with individual sling sutures (fig 18).

\footnotetext{
*Mepecaine hydrochloride: Septodont- France

** AlloDerm: BioHorizons- USA
} 
Periodontal pack (Coe-pack) was applied to both surgical sites (fig 11). Chlorhexidine mouthwash was prescribed postoperatively for oral rinse twice daily to maintain adequate oral hygiene. Ibuprofen $400 \mathrm{mg}$ analgesics three times a day was prescribed. Sutures were removed 2-weeks postoperatively. All patients were provided regular periodontal maintenance for six months.

\section{Statistical analysis}

The collected data were analyzed using a Statistical Package for the Social Sciences software program (IBM SPSS Statistics for Windows, Version 21.0. Armonk, NY: IBM Corp). Dependent t-test was used to evaluate the effectiveness of each treatment modality by comparing between baseline scores and the 6 months follow scores. Independent t-test was used to compare between the two treatments modalities. The level of significance was considered statistically significant at $\mathrm{p} \leq 0.05$.

\section{RESULTS}

Ten healthy patients diagnosed having bilateral maxillary or mandibular two to three adjacent Miller Class I or II gingival recession defects on canine or premolars participated in this study. Their age ranging from 34-60 years old (mean 43 years \pm 9.37 standard deviation). In (VISTA+ADM) sides a 24 recession defects (5 were located on mandibular canine, 7 on mandibular first premolar,
6 on mandibular second premolar, 1 on maxillary canine, 3 on maxillary first premolar and 2 on maxillary second premolar). While at (Tun+ADM) sides also a 24 recession defects (6 were located on mandibular canine, 7 on mandibular first premolar, 5 on mandibular second premolar, 1 on maxillary canine, 3 on maxillary first premolar and 2 on maxillary second premolar). All patients adequately tolerated the surgical procedures with no post operative complication.

\section{Clinical parameters}

Comparing between right side (VISTA+ADM) and left side $(T u n+A D M)$ at baseline and 6 months post-operative measurements:

Baseline measurement showed no statistical difference between both (VISTA+ADM) and (Tun+ADM) sides regarding RH, CAL, WKG and PD. Graph (1) Table (1)

After 6 months follow-up period a statistical significant difference exists between (VISTA+ADM) and (Tun+ADM) sides regarding $\mathrm{RH}$ and CAL. The average $\mathrm{RH}$ at the (VISTA+ADM) sides was $0.25 \pm 0.29$ while at (Tun+ADM) was $0.56 \pm 0.43$. Also the average CAL at the (VISTA+ADM) sides was $1.23 \pm 0.26$ while at the (Tun+ADM) was $1.63 \pm 0.42$. However, regarding WKG and PD a non significant difference exists between both sides. Graph (2) Table (2)

TABLE (1): Comparison between the clinical parameters of (VISTA+ADM) and (Tun+ADM) sides at baseline:

\begin{tabular}{|c|c|c|c|c|}
\hline Baseline measurements & $\begin{array}{c}\text { Root recession height } \\
\text { Mean } \pm \text { SD }\end{array}$ & $\begin{array}{c}\text { CAL } \\
\text { Mean } \pm \text { SD }\end{array}$ & $\begin{array}{c}\text { WKG } \\
\text { Mean } \pm \text { SD }\end{array}$ & $\begin{array}{c}\text { PD } \\
\text { Mean } \pm \text { SD }\end{array}$ \\
\hline Tun + ADM & $3.06 \pm 0.60$ & $4.44 \pm 0.56$ & $2.04 \pm 0.34$ & $1.42 \pm 0.46$ \\
\hline VISTA + ADM & $3.1 \pm 0.53$ & $4.38 \pm 0.54$ & $2.10 \pm 0.33$ & $1.31 \pm 0.32$ \\
\hline P-value & 0.799 & 0.744 & 0.532 & 0.368 \\
\hline
\end{tabular}

$P=p$ value calculated by Chi square test, $*$ = statistically significant. 
TABLE (2): Comparison between the clinical parameters of (VISTA+ADM) and (Tun+ADM) sides after 6 months:

\begin{tabular}{|l|c|c|c|c|}
\hline $\begin{array}{l}\text { Post-operative 6 months } \\
\text { follow-up period measurement }\end{array}$ & $\begin{array}{c}\text { Root recession height } \\
\text { Mean } \pm \text { SD }\end{array}$ & $\begin{array}{c}\text { CAL } \\
\text { Mean } \pm \text { SD }\end{array}$ & $\begin{array}{c}\text { WKG } \\
\text { Mean } \pm \text { SD }\end{array}$ & $\begin{array}{c}\text { PD } \\
\text { Mean } \pm \text { SD }\end{array}$ \\
\hline Tun + ADM & $0.56 \pm 0.43$ & $1.63 \pm 0.42$ & $3.33 \pm 0.46$ & $1.06 \pm 0.37$ \\
\hline VISTA + ADM & $0.25 \pm 0.29$ & $1.23 \pm 0.26$ & $3.38 \pm 0.37$ & $0.98 \pm 0.10$ \\
\hline P-value & $0.005^{*}$ & $0.00^{*}$ & 0.73 & 0.294 \\
\hline
\end{tabular}

$P=p$ value calculated by Chi square test, $*=$ statistically significant.

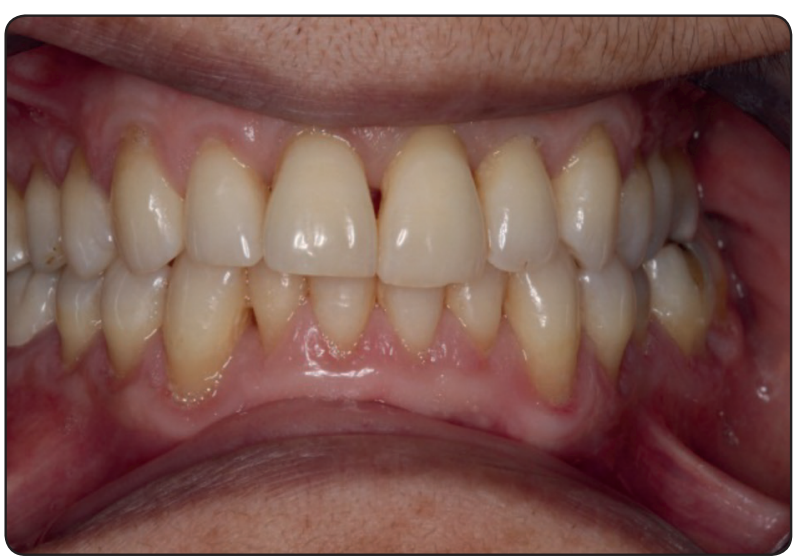

GRAPH (1)

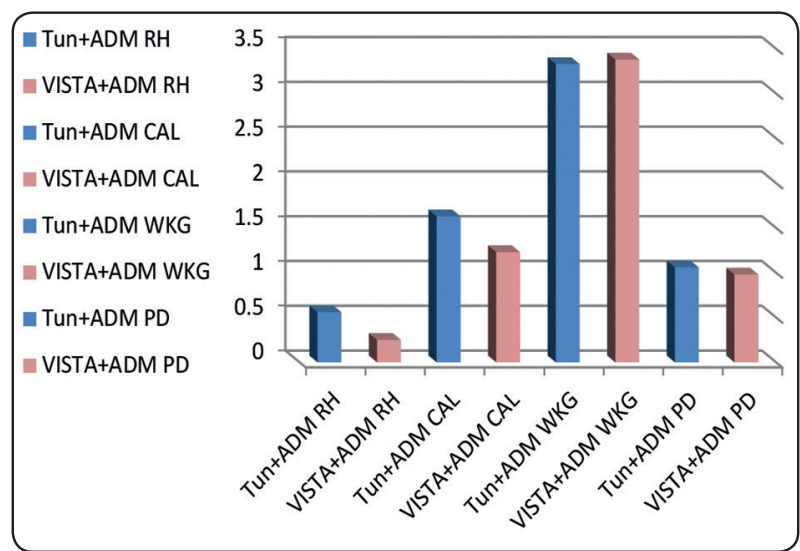

GRAPH (2)

\section{Changes within each side through the 6 months} follow-up period:

At the (VISTA+ADM) sides there was a statistically significant difference between baseline and 6 months follow-up measurements regarding $\mathrm{RH}, \mathrm{CAL}, \mathrm{WKG}$ and PD. The baseline RH measurement was $3.1 \pm 0.53 \mathrm{~mm}$ while after 6 months follow-up it significantly decreases to $0.25 \pm 0.29 \mathrm{~mm}$ and the CAL was $4.38 \pm 0.54 \mathrm{~mm}$ then decreases to $1.23 \pm 0.26 \mathrm{~mm}$ after 6 month follow-up. At the same time, the WKG was $2.10 \pm 0.33 \mathrm{~mm}$ at baseline measurements and increases to $3.38 \pm 0.37 \mathrm{~mm}$ after 6 months, while the PD was $1.31 \pm 0.32 \mathrm{~mm}$ at the baseline measurement and then decreases to $0.98 \pm 0.10 \mathrm{~mm}$ after 6 months follow-up period.
Graph (3) Table (3)

In (Tun+ADM) sides there was a statistically significant difference between baseline and 6 months follow-up measurements regarding $\mathrm{RH}, \mathrm{CAL}, \mathrm{WKG}$ and PD. At baseline RH was $3.06 \pm 0.60 \mathrm{~mm}$ while after 6 months follow-up it decreases to $0.56 \pm 0.43 \mathrm{~mm}$ and the CAL was $4.44 \pm 0.56 \mathrm{~mm}$ then decreases to $1.63 \pm 0.42 \mathrm{~mm}$ after 6 month follow-up. At the same time the WKG was $2.04 \pm 0.34 \mathrm{~mm}$ at baseline measurements and increases to $3.33 \pm 0.46 \mathrm{~mm}$ after 6 months, while the PD was $1.42 \pm 0.46 \mathrm{~mm}$ at the baseline measurement and then decreases to $1.06 \pm 0.37$ after 6 months follow-up period. Graph (4) Table (4) 
TABLE (3): Changes in (VISTA+ADM) side through the 6 months follow-up period:

\begin{tabular}{|c|c|c|c|c|}
\hline VISTA + ADM & $\begin{array}{c}\text { Root recession height } \\
\text { Mean } \pm \text { SD }\end{array}$ & $\begin{array}{c}\text { CAL } \\
\text { Mean } \pm \text { SD }\end{array}$ & $\begin{array}{c}\text { WKG } \\
\text { Mean } \pm \text { SD }\end{array}$ & $\begin{array}{c}\text { PD } \\
\text { Mean } \pm \text { SD }\end{array}$ \\
\hline Baseline & $3.1 \pm 0.53$ & $4.38 \pm 0.54$ & $2.10 \pm 0.33$ & $1.31 \pm 0.32$ \\
\hline $\begin{array}{c}\text { Post-operative } \\
6 \text { months }\end{array}$ & $0.25 \pm 0.29$ & $1.23 \pm 0.26$ & $3.38 \pm 0.37$ & $0.98 \pm 0.10$ \\
\hline P-value & $0.00^{*}$ & $0.00^{*}$ & $0.00^{*}$ & $0.00^{*}$ \\
\hline
\end{tabular}

$P=p$ value calculated by Chi square test,$*=$ statistically significant .

TABLE (4): Changes in (Tun+ADM) side through the 6 months follow-up period:

\begin{tabular}{|c|c|c|c|c|}
\hline Tun + ADM & $\begin{array}{c}\text { Root recession height } \\
\text { Mean } \pm \text { SD }\end{array}$ & $\begin{array}{c}\text { CAL } \\
\text { Mean } \pm \text { SD }\end{array}$ & $\begin{array}{c}\text { WKG } \\
\text { Mean } \pm \text { SD }\end{array}$ & $\begin{array}{c}\text { PD } \\
\text { Mean } \pm \text { SD }\end{array}$ \\
\hline Baseline & $3.06 \pm 0.60$ & $4.44 \pm 0.56$ & $2.04 \pm 0.34$ & $1.42 \pm 0.46$ \\
\hline $\begin{array}{c}\text { Post-operative } \\
6 \text { months }\end{array}$ & $0.56 \pm 0.43$ & $1.63 \pm 0.42$ & $3.33 \pm 0.46$ & $1.06 \pm 0.37$ \\
\hline P-value & $0.00^{*}$ & $0.00^{*}$ & $0.00^{*}$ & $0.00^{*}$ \\
\hline
\end{tabular}

$P=p$ value calculated by Chi square test,$*$ = statistically significant.

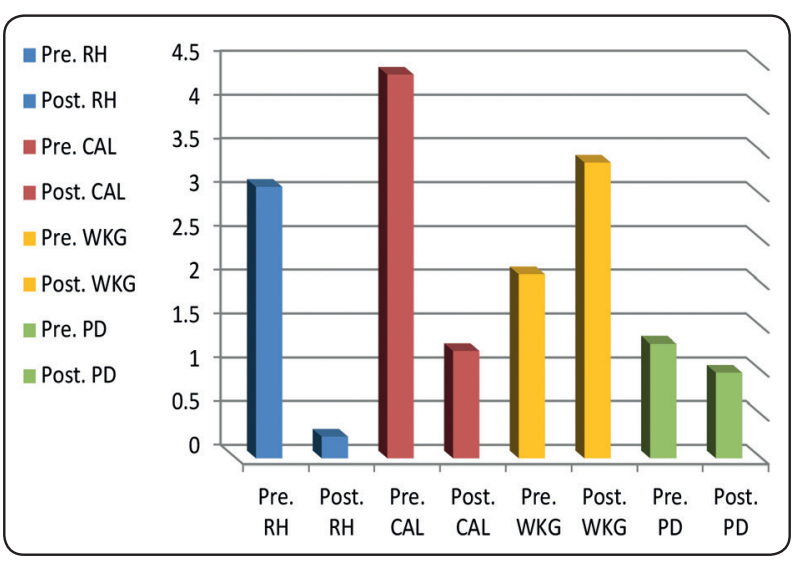

GRAPH (3)

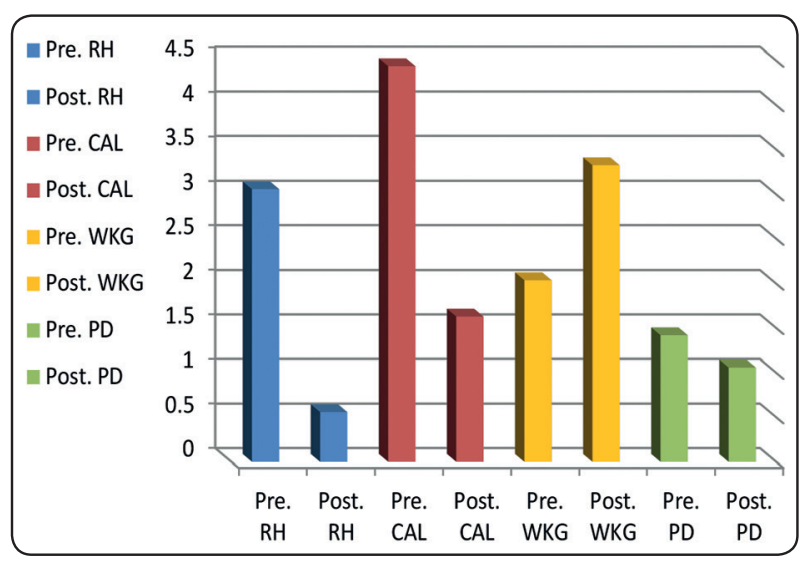

GRAPH (4)
Percentage of root coverage between (VISTA+ADM) and (Tun+ ADM) sides: Graph (5) Table (5)

At six months follow-up period the percentage of root coverage was $92.42 \pm 9.32$ in (VISTA+ADM) sides and $82.58 \pm 12.89$ in (Tun+ADM) sides. The difference between the two sides was statistically significant in favor of the (VISTA+ADM) with $\mathrm{p}$-value $=0.004$
TABLE (5): Comparison between (VISTA+ADM) and (Tun+ ADM) sides regarding percentage of root coverage:

\begin{tabular}{|l|c|c|c|}
\hline $\begin{array}{l}\text { Post-operative } \\
\text { after 6 months }\end{array}$ & (Tun+ ADM) & (VISTA+ADM) & P-value \\
\hline $\begin{array}{l}\text { Percentage of } \\
\text { root coverage }\end{array}$ & $82.58 \pm 12.89$ & $92.42 \pm 9.32$ & $0.004^{*}$ \\
\hline
\end{tabular}

$\mathbf{P}=p$ value calculated by Chi square test,

* = statistically significant. 


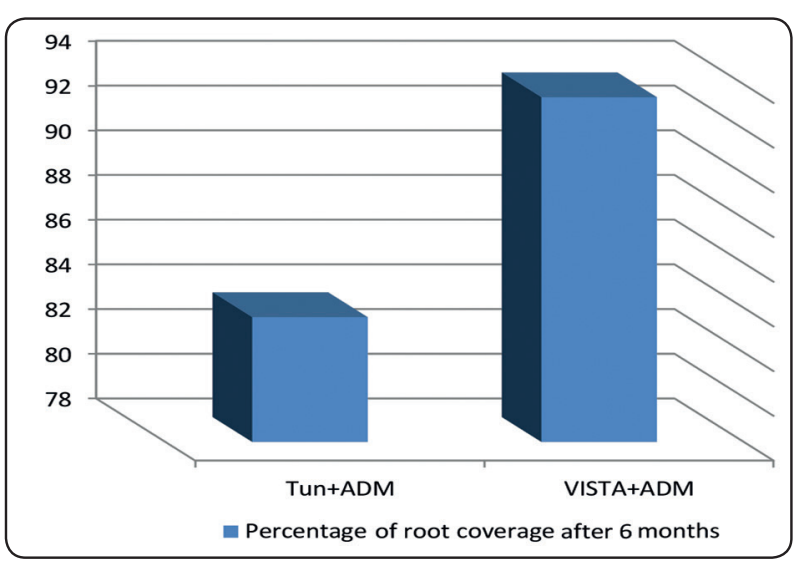

GRAPH (5)

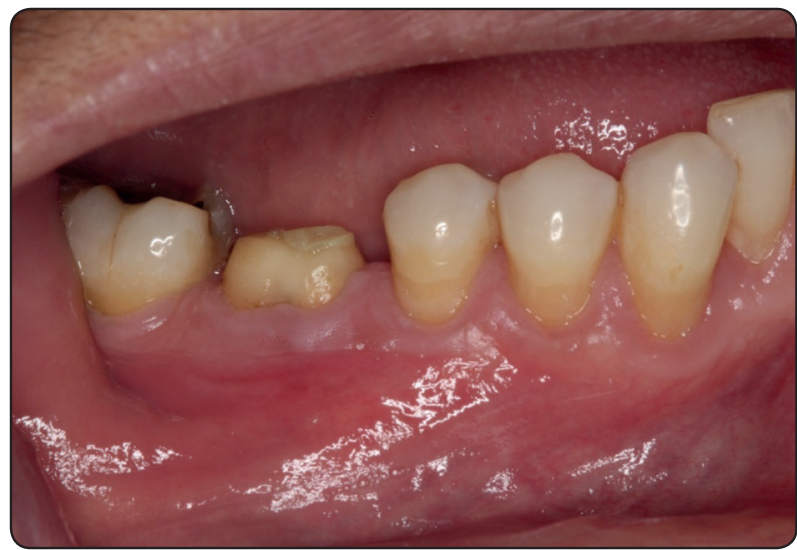

Fig. (2): Pre-operative photo of the right side (VISTA+ADM)

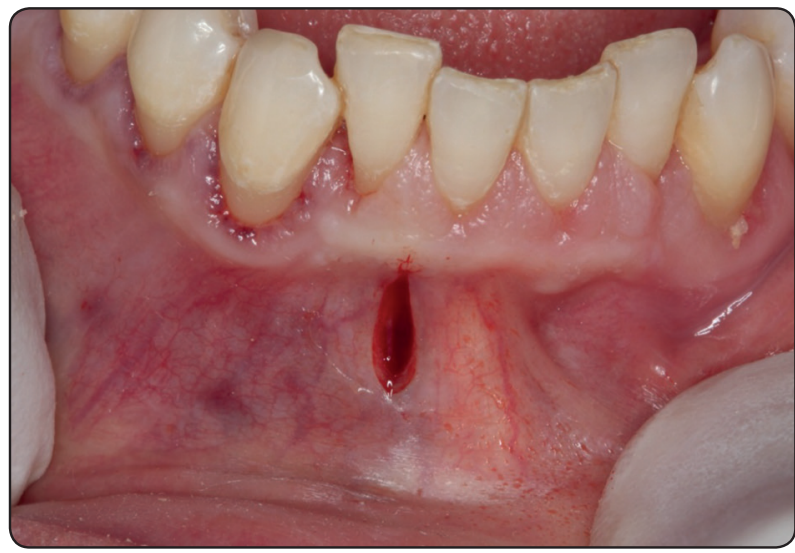

Fig. (4): Vestibular incision mesial to the gingival recession defects

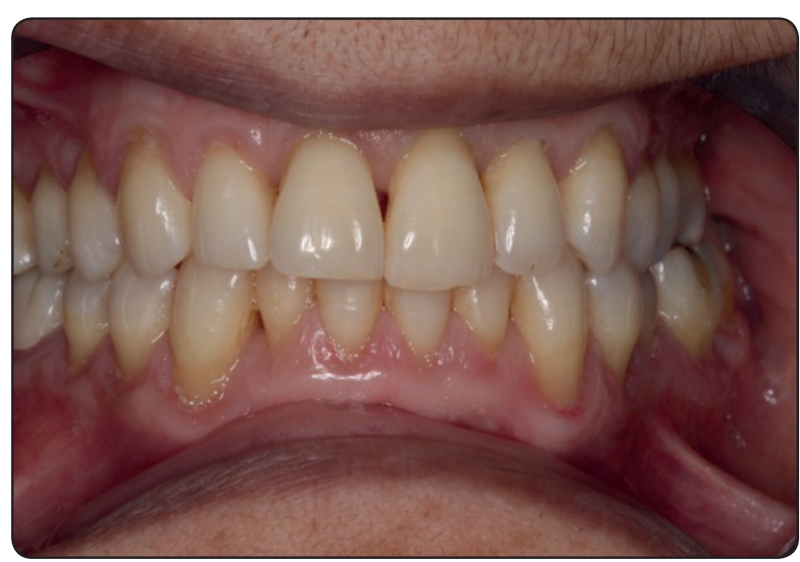

Fig. (1) Pre-operative photo showing bilateral Mandibular, Miller Class I and II gingival recession

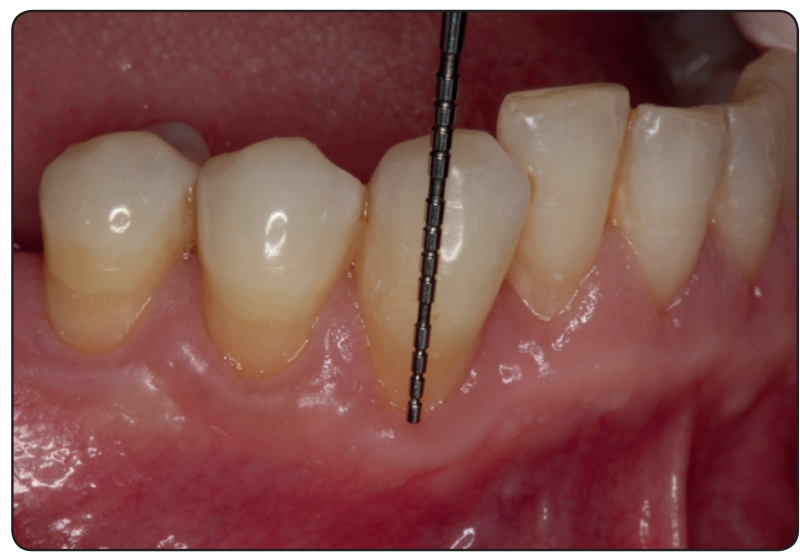

Fig. (3): Recession height measured mid-bucally with UNC 15 Color-Coded Probe

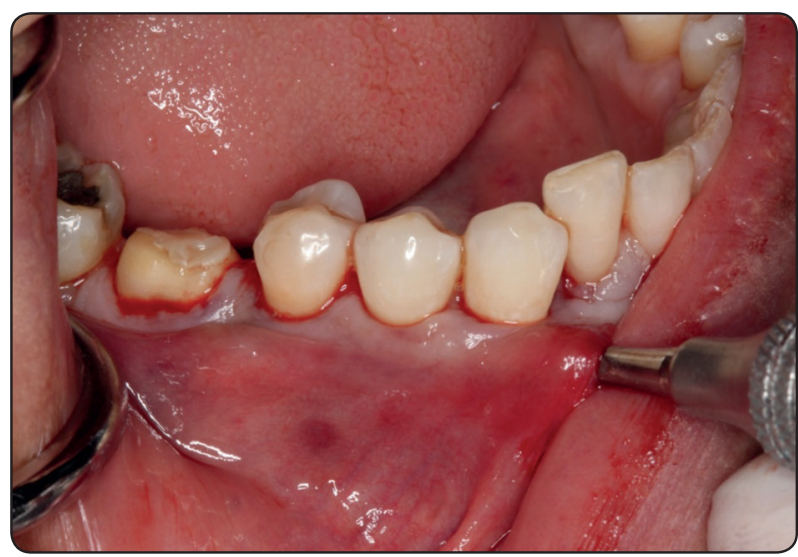

Fig. (5): Subperiosteal tunnel was created using Allen oral plastic surgery kit 


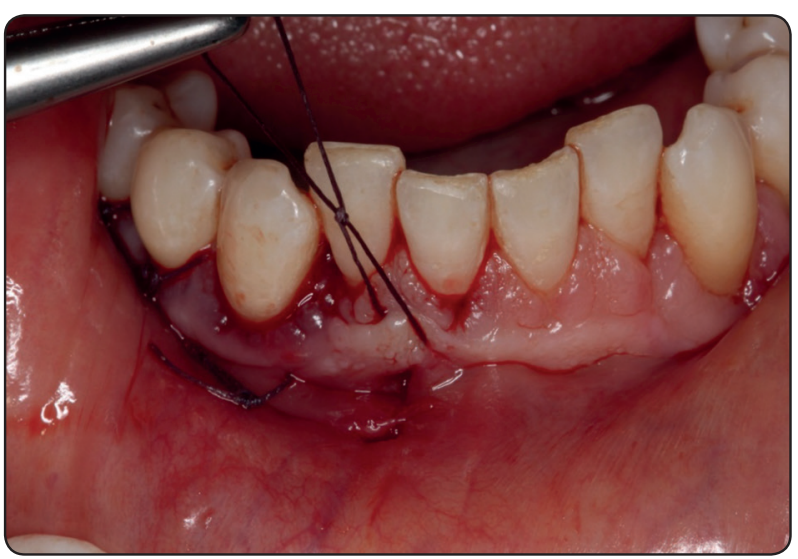

Fig. (6): Horizontal mattress suture at approximately 2-3 mm apical to gingival margin

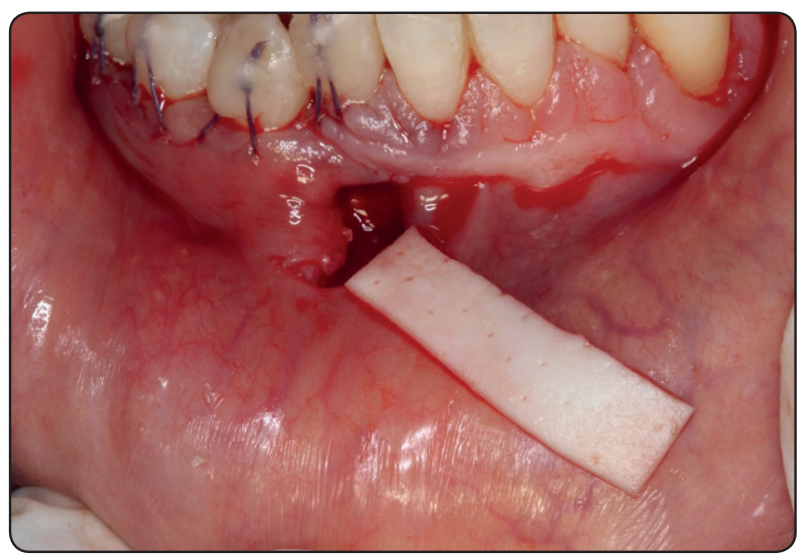

Fig. (8): ADM that was soaked in saline solution for 30 minutes before insertion through the subperiosteal tunnel

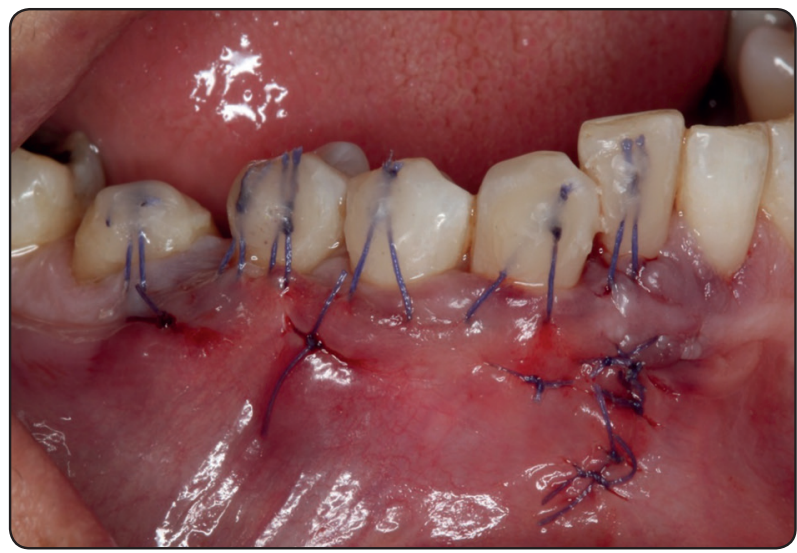

Fig. (10): ADM was sutured to the flap using multiple anchor sutures and vertical incision was then approximated and sutured

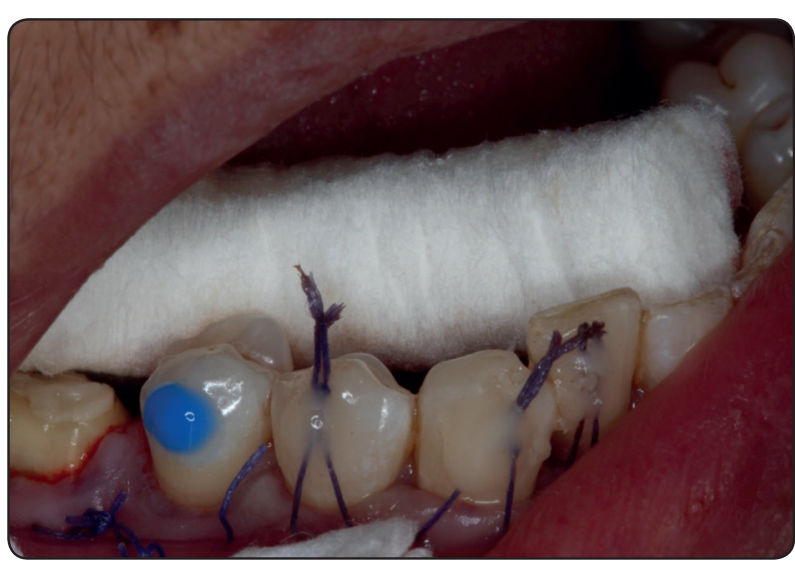

Fig. (7): Sutures were tied with the knots at the mid-coronal point of the facial surface of the tooth and secured with composite resin to restrain any apical movement of the tissues

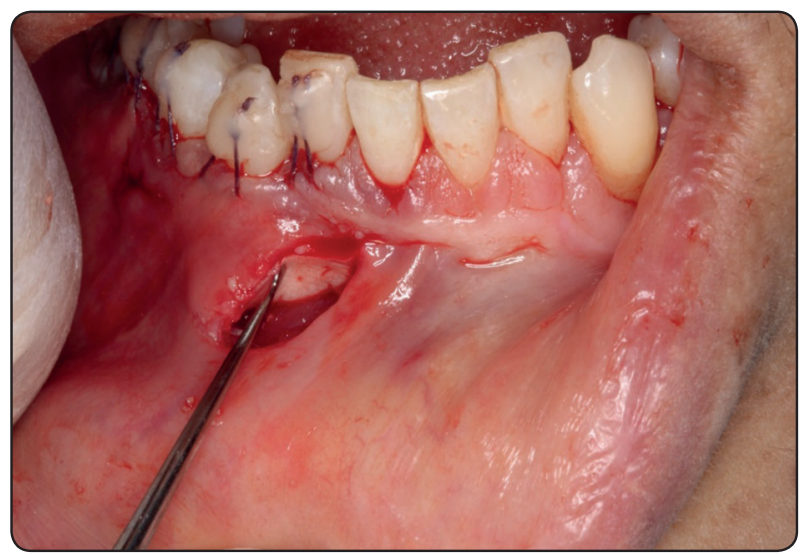

Fig. (9): ADM was inserted through the subperiosteal tunnel with help of an elevator or pulled through the tunnel at the level of CEJ

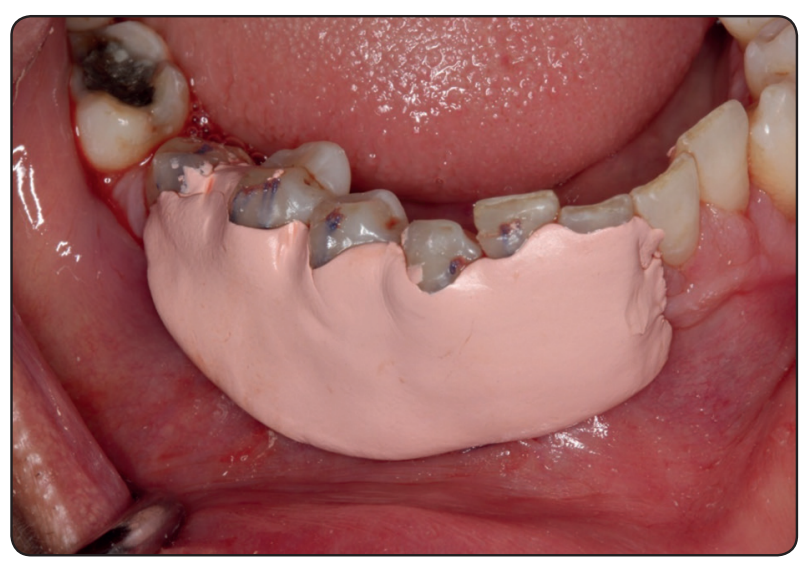

Fig. (11): Periodontal pack (Coe-pack) was applied to the surgical site. 


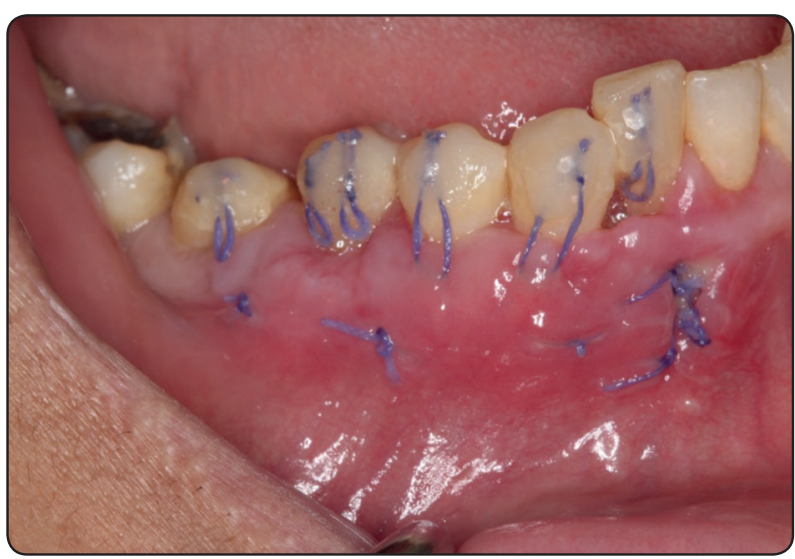

Fig. (12): Two weeks postoperatively at the time of sutures removal

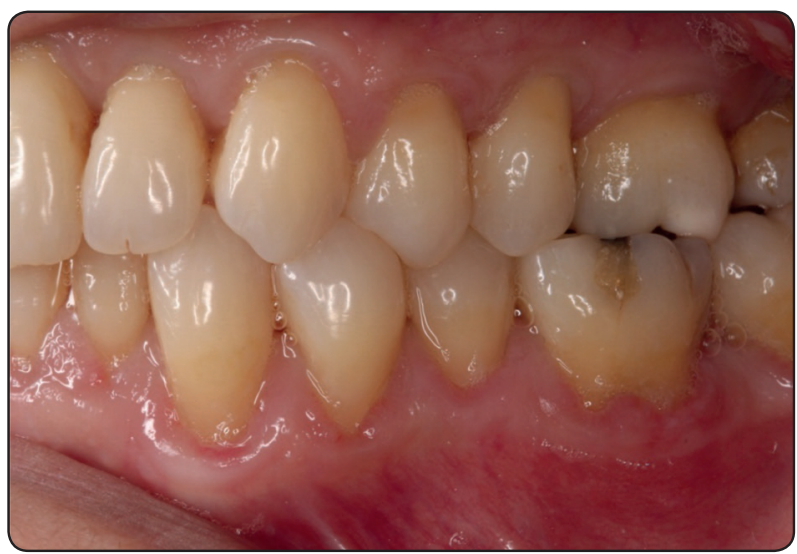

Fig. (14): Pre-operative photo of the left side (Tun+ADM)

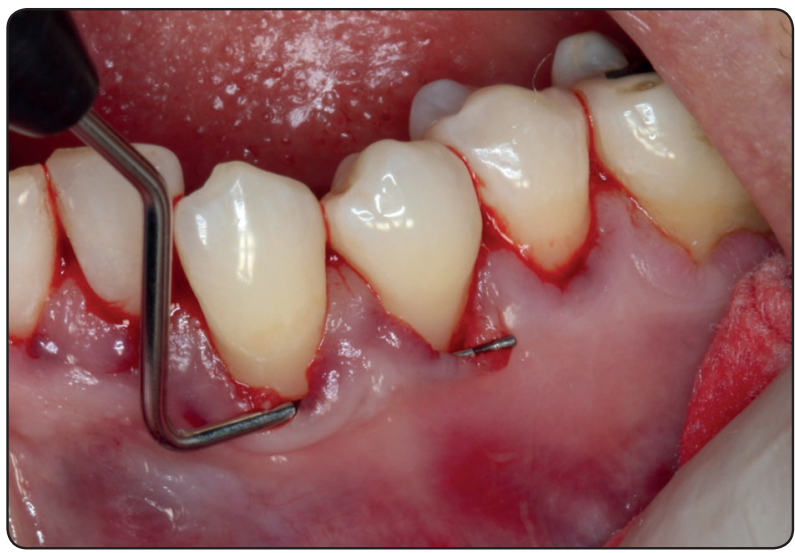

Fig. (16): Tunnel was created through the sulcular incision using Allen oral plastic surgery kit

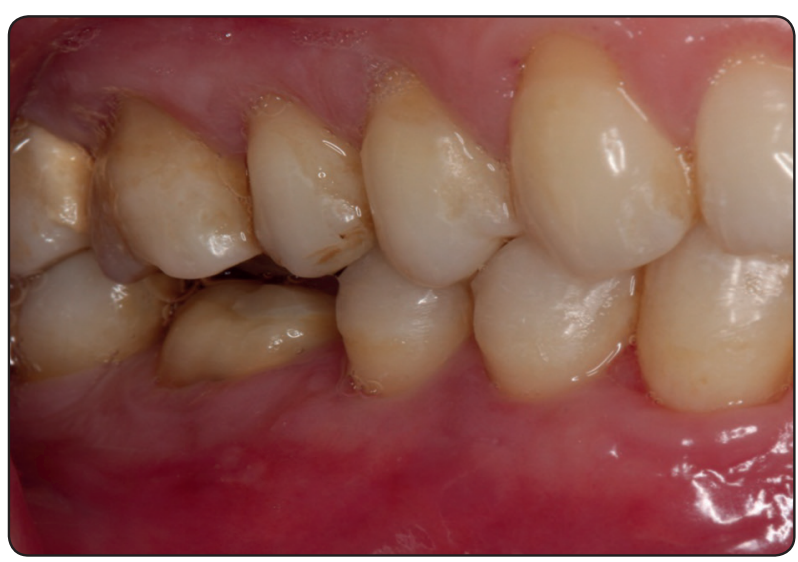

Fig. (13): Six months post-operative showing complete root coverage.

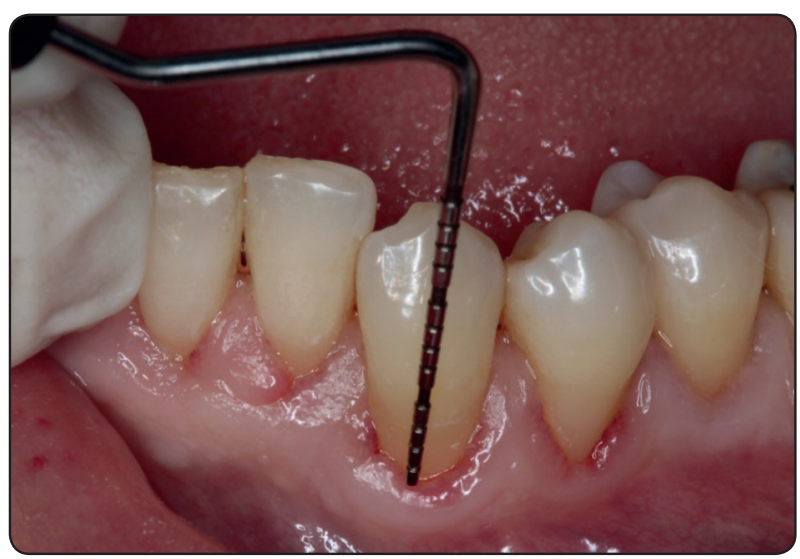

Fig. (15): Recession height measured mid-bucally with UNC 15 Color-Coded Probe

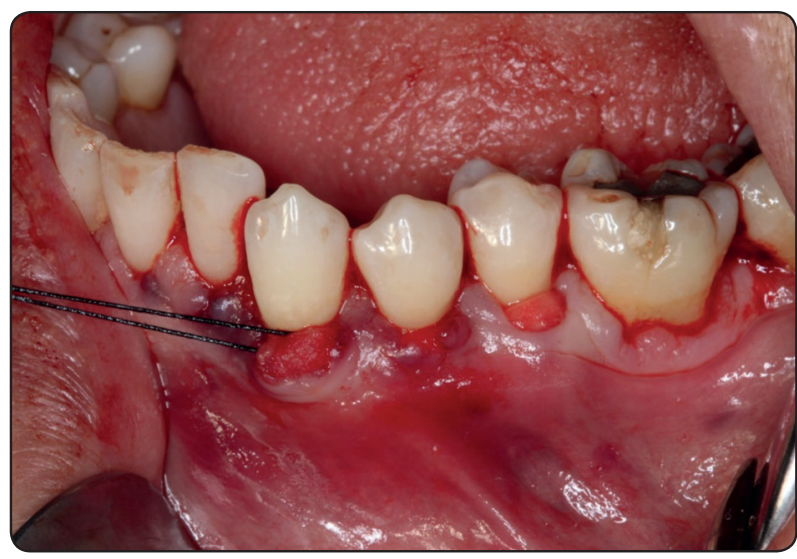

Fig. (17): ADM was inserted and pulled through the tunnel with a suture at the level of CEJ 


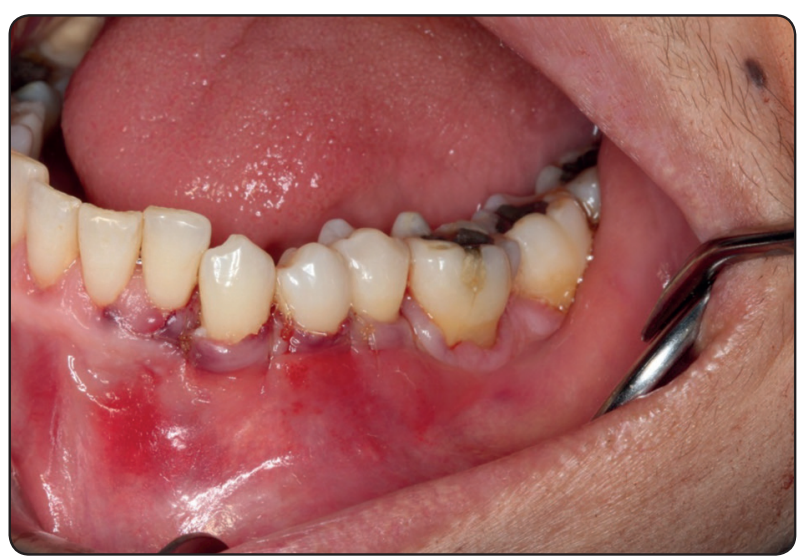

Fig. (18): Flap was closed with individual sling sutures.

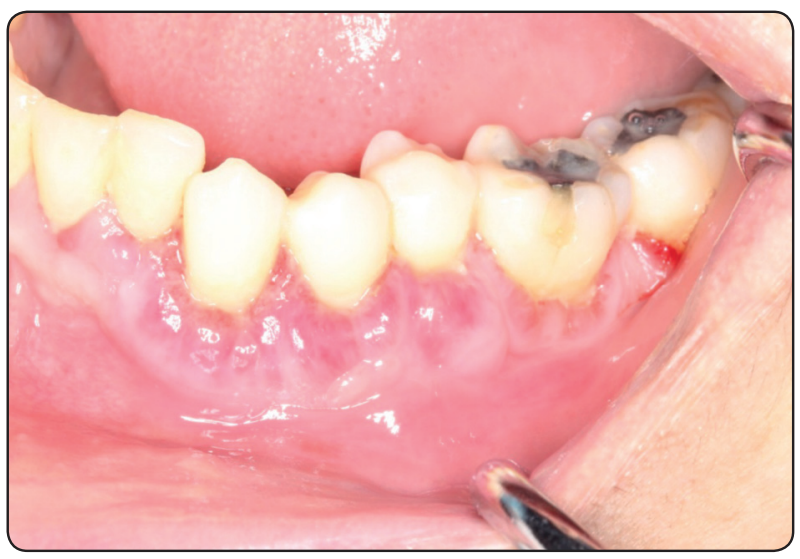

Fig. (19): Two weeks postoperatively after sutures removal

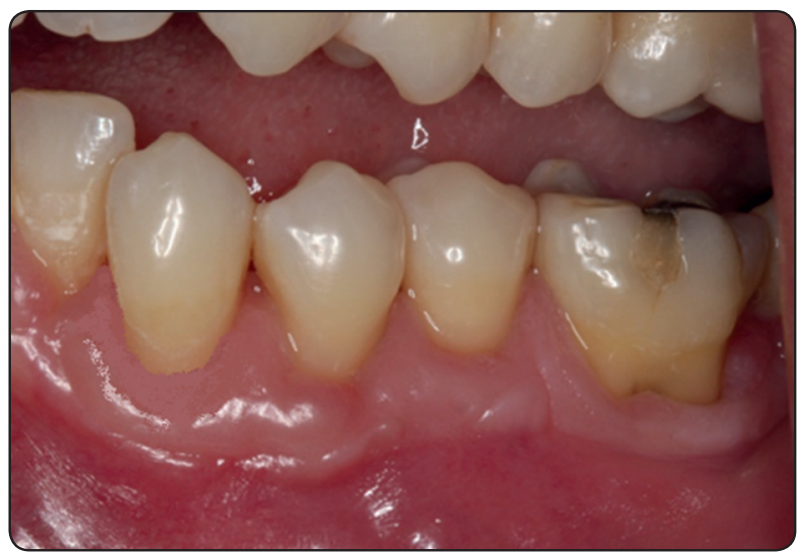

Fig. (20): Six months post-operative showing partial root coverage.

\section{DISSCUSSION}

Gingival recession is considered a major esthetic problem for many patients. A wide range of therapeutic alternative exist for treatment of isolated or multiple gingival recessions. ${ }^{18}$ The choice of the suitable treatment modalities depends on the gingival height, width of keratinized gingival, level of alveolar bone and interdental papillae, gingival tissue type and other esthetic demands. ${ }^{19,20}$ Envelope or tunnel technique is considered a suitable treatment modality for multiple adjacent recessions. ${ }^{21}$ However, the traditional tunnel technique was found to be sensitive and timeconsuming. ${ }^{22}$ VISTA technique presents advantages over the traditional tunnel technique in treatment of multiple gingival recessions. It provides a wider access to the entire surgical region and improves visualization through the single vestibular incision. Preservation of circulation in an apico-coronal direction is mandatory for treatment success. At the same time, vertical incision allows the detection of any tissue tags which will disrupt the continuity of the traditional tunnel technique..$^{18,23}$

In the present study a comparison was done between using Tunnel or VISTA techniques in treatment of multiple gingival recessions accompanied with acellular dermal matrix allograft. ADM was preferred over using connective tissue graft to eliminate the need of a donor surgical site and its complications. Various complications could occur as bleeding, swelling and post operative pain. ${ }^{24}$ Several studies evaluated the effectiveness of using acellular dermal allograft in treatment of multiple gingival recession defects. Most of the studies reported $90 \%$ root coverage ${ }^{25-29}$, while Ozenci et al 2015 reached only $75 \%$ root coverage through using Tun+ADM in treatment of multiple gingival recessions. ${ }^{30}$

In this study both treatment modalities were significantly effective in improving the clinical parameters RH, CAL, WKG and PD from baseline till six month follow-up period. At the (Tun+ADM) sides 
the RH decreases significantly from $3.06 \pm 0.60 \mathrm{~mm}$ at baseline to $0.56 \pm 0.43 \mathrm{~mm}$ after 6 months. Also the (VISTA+ADM) sides showed decrease in RH from $3.1 \pm 0.53 \mathrm{~mm}$ at baseline to $0.25 \pm 0.29 \mathrm{~mm}$ after 6 months follow-up period. A significant difference in $\mathrm{RH}$ and $\mathrm{CAL}$ exists between the two groups at six months follow-up which was in favor of the (VISTA+ADM) treatment with pvalue equal 0.005 and 0.00 respectively. Also at six months the percentage of root coverage was $82.58 \pm 12.89$ in (Tun+ADM) sides and $92.42 \pm 9.32$ in (VISTA+ADM) sides. This difference was statistically significant in favor of the (VISTA+ADM) with $\mathrm{p}$-value $=0.004$.

In tunnel technique the only access is provided through the gingival sulcus which is difficult and might cause tearing for the gingival papillae. Also the space allowed for ADM placement is small and inaccessible. While in VISTA technique the single vertical incision mesial to the defect decreases the possibility of traumatizing the gingival and allows easier accessibility for ADM intrusion. At the same time the integrity and vascularity of delicate papillae are maintained facilitating the healing process. ${ }^{23,31}$

In 2002, Mahn $\mathrm{DH}^{32}$ uses modified tunnel technique and $\mathrm{ADM}$ in correction of gingival recession in anterior teeth. He concluded that this combination technique is relatively atraumatic and resulted in highly esthetic appearance. This result was compatible with our study suggesting the use of VISTA technique with ADM. Gupta et al 2015, ${ }^{33}$ found that using VISTA technique along with plateletrich fibrin provided optimal esthetic results and perfect soft tissue biotype. Also Pratiwi \& Setiawatie $2019^{34}$, in a case report used minimal invasive VISTA technique with ADM and platelet rich fibrin in treatment of multiple gingival recessions. They found that VISTA technique was effective in maintaining vascularity and papillary integrity. Also ADM as autogenous graft supported the natural revascularization and allows tissue remodeling beside cell repopulation. They recommended additional clinical studies with a larger number of patients for better assessment of VISTA technique in treatment of multiple gingival recessions.

In conclusion, the use of Acellular Dermal Matrix allograft is recommended in treatment of multiple gingival recessions and could be an alternative for connective tissue autograft. Its combination with VISTA technique was found to be more efficient than Tun+ ADM in treatment of Miller class I and II gingival recessions and led to favorable root coverage.

\section{REFERENCES}

1. Barros RR, Novaes AB, Grisi MF, Souza SL, Taba MJ, Palioto BD. A 6-month comparative clinical study of a conventional and a new surgical approach for root coverage with Acellular Dermal Matrix. J Periodontol, 2004 Oct; 75(10): 1350-6.

2. Koshy BS, Mahendra J, Vijayalakshmi R. Platelet-Rich Fibrin-Reinforced Vistibular Incision Subperiosteal Tunnel Access (VISTA) Technique for multiple Root Coverage. A case report. J of Cochin Periodontists Society. 2016; 1(2): 116-119.

3. Rahmani, Lades MA. Comparative clinical evaluation of Acellular Dermal Matrix Allograft and Connective tissue graft for the treatment of gingival recession. J Contemp Dent Pract. 2006 May; 7(2): 63-70.

4. Krismariono A. Prinsip dasar perwatan resesi gingival (Basic principle in the treatment of gingival recession). Dentika Dent J. 2014; 18(1): 96-100.

5. Rutuja KP, Lisa C, Rakhewar PS, Shah TH. The vestibular incision subperiosteal tunnel access (VISTA) for treatment of maxillary anterior gingival recession defects: A case report. Int J Health Sci Res. 2017; 7(7): 360-5.

6. Sabarinathan J, Prabhu MN, Lo Tzelui, Chung V, Tan Shiau Lin, Chew V, KhoAik Jin. Prevalence of gingival recession among the different races of patients reporting to Penang International Dental College. Int J Dent Sci Res. 2014; 2(4A): 1-3.

7. Cairo F, Pagliaro U, et al. Treatment of gingival recession with coronally advanced flap procedures: A systematic review. J of clinical periodontology. 2008; 35:136-162.

8. Chambrone L, Araujo, et al. Root coverage procedures for the treatment of localized recession-type defects. Cochrane Database Systematic Review. 2009; CD007161. Pub2. 
9. Buti J, Baccini M, et al. Bayesian network meta-analysis of root coverage procedure: ranking efficacy and identification of best treatment. J Clin periodontal. 2013;40: 372-386.

10. Dridi SM, Chousterman M, Danan M, Gaudy JF. Heamorrhagic risk when harvesting palatal connective tissue grafts: a reality? J Perio. 2008; 5(4): 231-240.

11. Chenchev IV, Neichev D, Vincheva D, Atanasov D, Noncheva V. Vista technique and Platelet-Rich Fibrin Membrane for treatment of multiple adjacent gingival recessions -6 minth follow-up. J of Dental and Medical Sciences. 2016; 15(7): 128-133.

12. Modaressi M, Wang HL. Tunneling procedure for root coverage using acellular dermal matrix: A case series. Int $\mathbf{J}$ Periodontics Restorative Dent. 2014; 29(4): 395-403.

13. Joly JC, Carvalho AM,da Silva RC, Ciotti DL, Cury PR. Root coverage in isolated gingival recessions using autograft versus allograft: A pilot study. J Periodontol. 2007; 78: 1017-1022.

14. Felipe ME, Andrade PF, Grisi MFM, et al.Comparison of two surgical procedures for use of the acellular dermal matrix graft in the treatment of gingival recessions: A randomized controlled clinical study. J Periodontol. 2007; 78: 1209-1217.

15. Papageorgakopoulos G, Greenwell H, Hill M, Vidal R, Scheetz JP. Root coverage using acellular dermal matrix and comparing a coronally positioned tunnel to a coronally positioned flap approach. J Periodontol. 2008; 79:1022-1030.

16. Zadeh HH. Minimally invasive treatment of maxillary anterior gingival recession defects by vestibular incision subperiosteal tunnel access and platelet-derived growth factor BB. Int J Periodontics Restorative Dent. 2011; 31:653-660.

17. Azzi R,Etienne D. Root coverage and papilla reconstruction by connective tissue graft inserted under a vestibular coronally advanced tunnelized flap. J de P[arodontologie et Implantologie Oralee. 2001;17:71-77.

18. Rajeswari R, Kurmar TA, Gowda TM, Mehta DS, Kumar A. Management of multiple gingival recessions with the VISTA technique: An 18-month clinical case series. 2018; 38(2): 245-251.

19. Shkreta M, Atanasovska-Stojanovska A, Dollaku B, Belazelkoska Z. Exploring the gingival recession surgical treatment modalities: A literature review. J Med Sci. 2018; 6(4): 698-708.
20. Jasser AR, Alkudmani H,Andreana S. Platelet rich fibrin as a new approach in treating gingival recession: Systematic review and meta-analysis. J Dent Oral DisordTher. 2017; 5(2): $1-12$.

21. Mormann W, Meier C, Firestone A. Gingival blood circulation after experimental wounds in man. J Clin Periodontol. 1979; 6: 417-424.

22. Zabalegui I, Sicilia A, Cambra J, et al.Treatment of multiple adjacent gingival recessions with the tunnel subepithelial connective tissue graft: A clinical report. Int J Periodont Rest Dent. 1999; 19(2): 199-206.

23. Mahn DH. Treatment of gingival recession with a modified tunnel technique and an acellular dermal connective tissue allograft. Pract Proced Aesthet Dent. 2001; 13(1): 69-74.

24. Gayathri GV, Choundary S, Bharath N, Shilpa E, Mehta DS. Treatment of gingival recession with coronally advanced flap combined with connective tissue graft/ alloderm: A systematic review. Int J Oral Health Sci. 2014; 4: 70-80.

25. Thakare P, Baliga V, Bhongade ML. Comparative evaluation of the effectiveness of acellular dermal matrix allograft and subepithelial connective tissue to coronally advanced flap alone in the treatment of multiple gingival recessions: a clinical study. J Indian Soc Periodontol. 2015;19(5): 537-44

26. Koudale SB, Charde PA, Bhongade ML. A comparative clinical evaluation of acellular dermal matrix allograft and sub-epithelial connective tissue graft for the treatment of multiple gingival recessions. J Indian Soc Periodontol. 2012; 16(3): 411-6.

27. Thombre V, Koudale SB, Bhongade ML. Comparative evaluation of the effectiveness of coronally positioned flap with or without acellular dermal matrix allograft in the treatment of multiple marginal gingival recession defects. Int J Periodontics Restorative Dent. 2013; 33(3):e88-94.

28. Ahmedbeyli C, Ipci SD, Cakar G, Kuru BE, Yilmaz S. Clinical evaluation of coronally advanced flap with or without acellular dermal matrix graft on complete defect coverage for the treatment of multiple gingival recession with thin tissue biotype. J Clin Periodontol. 2014; 41(3):303-10.

29. Chaparro A, De la Fuente M, Albers D, Hernandez D, Villalobos AM, Gaedechens D, et al. Root coverage of multiple Miller Class I and II recession defects using acellular dermal matrix and tunneling technique in 
maxilla and mandible: a 1-year report. Int J Periodontics Restorative Dent. 2015; 35(5): 639-45.

30. Ozenci I, Ipci SD, Cakar G, Yilmaz S. Tunnel technique versus coronally advanced flap with acellular dermal matrix graft in the treatment of multiple gingival recessions. J Clin Periodontol. 2015; 42(12): 1135-42.

31. Reddy S, Prasad MGS, Bhowmik N, Singh S, Pandit HR, Vimal SK. Vestibular incision subperiosteal tunnel access (VISTA) with platelet rich fibrin (PRF) and connective tissue graft (CTG) in the management of multiple gingival recession: A case series. Int J Appl Dent Sci. 2016; 2(4): 34-7.
32. Mahn DH. Esthetic correction of gingival recession using a modified tunnel technique and an acellular dermal connective tissue allograft. J Esthet Restor Dent. 2002; 14:18-23.

33. Gupta G, Puri K, Bansal M, Khatri M, Kumar A. Plateletrich fibrin-reinforced vestibular incision subperiosteal tunnel access technique for recession coverage. Clinical Advances in Periodontics. 2015; 5(4): 248-253.

34. Pratiwi R, Setiawatie EM. Multiple gingival recession coverage treated with VISTA technique using acellular dermal matrix (ADM) combined with platelet rich fibrin (PRF): A case report. ODONTO Dental Journal. 2019; 6(1): 56-61. 